\title{
Nucleolus organizer regions and nucleoli in preattachment bovine embryos
}

\author{
W. A. King, A. Niar, I. Chartrain, K. J. Betteridge* and P. Guay \\ Centre de recherche en reproduction animale, Faculté de médecine vétérinaire, \\ Université de Montréal, C.P. 5000, St-Hyacinthe, Québec, Canada J2S 7C6
}

\begin{abstract}
Summary. Embryos (1-cell to elongated blastocyst stage) were recovered from superovulated heifers at surgery (Days $2-4$; oestrus $=$ Day 0 ), after slaughter (Day 4 ), or by transcervical flushing (Days 6, 7 and 14). The 175 embryos were cultured for 4, 8, 24 or $48 \mathrm{~h}$, fixed on slides and sequentially stained with Giemsa and silver nitrate. Twentythree 2-cell to blastocyst-stage embryos were fixed, embedded and examined by transmission electron microscopy. Argentophilic nucleolus organizer regions (Ag-NORs), indicative of transcriptionally active rRNA genes, were observed in embryos in which short- or long-term culture began at or after the late 8-cell stage. The nucleoli of embryonic cells also showed increased affinity for silver from the 8-cell stage onward. Differences in the number of Ag-NORs observed after the 8-cell stage reached statistical significance only when Day-5 and Day-7 embryos cultured for $4 \mathrm{~h}$ were compared. Ultrastructurally, the nucleoli were seen to develop from small, dense, fibrillar masses at the 2-cell stage, to ring-shaped structures (signifying a low level of activity) at the 8 -cell stage. At the 16-cell stage the nucleoli became reticulated, suggesting an increase in activity, and by the morula and blastocyst stages they were characteristic of fully active nucleoli.

It is concluded that a significant transcriptional activity of the rRNA genes in the embryos of cattle begins around the 8-cell stage.
\end{abstract}

Keywords: argentophilic nucleolus organizer regions; bovine embryos; RNA gene activity

\section{Introduction}

Nucleolus organizer regions (NORs) are the chromosomal locations where genes which code for ribosomal RNA (rRNA) are clustered. The nucleoli form at the NORs and are the sites where pre-ribosomal RNA is synthesized, processed and assembled with proteins into pre-ribosomal particles. The number of NORs, like the chromosome number, is characteristic of the species. However, within a species the number, size and shape of nucleoli vary with the organ, cell type and physiological state of the cell, the morphological features of nucleoli reflecting the intensity of their activity (for review see Goessens, 1984).

Nucleoli have an affinity for silver. Depending on staining conditions, silver nitrate reacts with acidic nucleolar proteins in the nucleolus (Schwarzacher et al., 1978) and on the NORs of metaphase chromosomes (Bloom \& Goodpasture, 1976). Because silver staining of metaphase chromosomes detects functional NORs that were active during the preceding interphase (Croce et al., 1977), this reaction provides a means of visualizing the activity of rRNA genes in individual cells.

At the ultrastructural level, three distinct types of nucleoli have been recognized: ring-shaped, reticulated and compact (Smetana \& Busch, 1974). Studies involving stimulated and unstimulated

\footnotetext{
*Present address: Department of Biomedical Sciences, Ontario Veterinary College, University of Guelph, Guelph,
} Ontario, Canada N1G 2W1. 
lymphocytes have revealed that ring-shaped nucleoli have low transcriptional activity, reticulated nucleoli appear at the beginning of a period of intense transcriptional activity, and compact nucleoli occur in fully active cells (Wachtler et al., 1980).

Immediately after fertilization the embryonic genome is essentially quiescent, with metabolism being directed by maternally derived messages already present in the ooplasm. In the mouse, there is evidence that RNA of embryonic origin is present by the 2-cell stage and is essential for continued development (Kidder \& McLachlin, 1985). Since silver-stained NORs (Ag-NORs) are present on at least one metaphase chromosome at the 2-cell stage in mice (Engel et al., 1977; Hansmann et al., 1978), some activity of the rRNA genes during interphase of the first cleavage can be inferred. However, the nucleoli at this stage are reported to be dense and agranular which suggests that NOR activity is absent (Geuskens \& Alexandre, 1984). By the blastocyst stage the maximum number of Ag-NORs characteristic of the mouse can be observed (Engel et al., 1977; Hansmann et al., 1978) and the nucleoli are fully active (Fakan \& Odartchenko, 1980; Geuskens \& Alexandre, 1984).

Although the morphology of bovine embryos has been studied extensively, little is known of when the embryonic genome is activated and expressed. Here we report an investigation of the time of appearance of Ag-NORs and the ultrastructural features of the nucleoli in preattachment bovine embryos. Part of this work has been reported in abstract form (King et al., 1985).

\section{Materials and Methods}

Embryo collection. Embryos were recovered from 36 grade Canadian Holstein heifers induced to superovulate by treatment with follicle-stimulating hormone (FSH-p; Burns-Biotech Laboratory, Oakland, CA, U.S.A.) injected i.m. twice daily in decreasing doses $(5,5 ; 4,4 ; 3,3 ; 2,2 ; 1,1 \mathrm{mg})$ for 5 days starting between Days 9 and 13 of the cycle (oestrus $=$ Day 0 ) and a single i.m. injection of $500 \mu \mathrm{g}$ cloprostenol (Estrumate; ICI Pharma, Mississauga, Ontario, Canada) $72 \mathrm{~h}$ after the initial FSH injection. The onset of the induced oestrus was determined by behavioural observations made twice daily. Collections were made surgically on Days 2, 3 and 4 (6,4 and 1 animals, respectively), after slaughter in one case on Day 4, or by a routine non-surgical transcervical procedure on Days 5, 6, 7 and 14 (7, 7,8 and 2 heifers, respectively). The surgical recoveries were made through a mid-ventral abdominal incision under general anaesthesia (Betteridge \& Mitchell, 1974). Before surgery, animals were deprived of food for $36-48 \mathrm{~h}$ and of water for $24 \mathrm{~h}$. Anaesthesia was induced by intravenous injection of thiamylal sodium $(10 \mathrm{mg} / \mathrm{kg}$ body weight $)$ and maintained by halothane in oxygen in a closed-circuit system. Routine veterinary care was provided post-operatively. For all types of collection, the flushing medium was Dulbecco's phosphate-buffered saline (PBS, pH 7.2) supplemented immediately before use with $2 \%$ fetal calf serum (FCS; Gibco, Burlington, Ontario, Canada) and antibiotics (100 i.u. penicillin, $100 \mu \mathrm{g}$ streptomycin $/ \mathrm{ml}$ ).

Culture procedures. Immediately after collection, embryos were washed in fresh PBS flushing medium and transferred to culture dishes. Embryos collected between Days 2 and 7 were incubated in a culture medium (pH 7.2) consisting of PBS enriched with sodium pyruvate $(36 \mu \mathrm{g} / \mathrm{ml})$, glucose $(1 \mathrm{mg} / \mathrm{ml})$, FCS $(20 \%)$ and antibiotics $(100$ i.u. penicillin, $100 \mu \mathrm{g}$ streptomycin $/ \mathrm{ml}$ ) at $37^{\circ} \mathrm{C}$ in a humid atmosphere. Day- 2 embryos were cultured for 8 or $48 \mathrm{~h}$, with colcemid $(0.05 \mu \mathrm{g} / \mathrm{ml}$; Gibco, Burlington) added to the culture medium for the duration of the 8 -h cultures and the last $4 \mathrm{~h}$ of the 48-h culture. Day-3 and Day-4 embryos were incubated in the medium containing colcemid for $8 \mathrm{~h}$. Embryos collected on Days 5, 6 and 7 were incubated for 4,24 or $48 \mathrm{~h}$, with colcemid $(0.05 \mu \mathrm{g} / \mathrm{ml})$ included in the culture medium for the entire 4-h incubation and the last $4 \mathrm{~h}$ of the 24- and 48-h incubations. Day-14 embryos were incubated for $4 \mathrm{~h}$ in Eagle's minimum essential medium (MEM; Gibco, Burlington) containing 20\% FCS and colcemid $(0.05 \mu \mathrm{g} / \mathrm{ml})$.

Cytology. Fixation on slides was performed as previously described for Day-2 to Day-7 embryos by King $e t$ al. (1979) and for Day-14 embryos by Romagnano et al. (1985). These slides were then lightly stained with Giemsa and examined. Those in which the chromosomes or nuclei were adequately spread were destained in methanol:acetic acid $(3: 1 \mathrm{v} / \mathrm{v})$, air-dried, and restained with an aqueous solution of silver nitrate for $18 \mathrm{~h}$ in a humid atmosphere at $50^{\circ} \mathrm{C}$ (Bloom \& Goodpasture, 1976). Slides were then re-examined and, if judged to be adequately stained, they were rinsed in distilled water and counter-stained for $10 \mathrm{sec}$ in a $1 \%$ Giemsa solution. Otherwise, incubation was continued for a further $8-10 \mathrm{~h}$ before rinsing and counter-staining. Argentophilic NORs and nucleoli on up to 10 nuclei per embryo were counted and photographed.

Statistics. The numbers of NORs per metaphase per embryo at each stage of development or after culture were compared using one factorial analysis of variance (Winer, 1971). The individual means were compared using the Scheffe F-test when the criterion of significance was $P<0.05$. 
Electron and light microscopy. Embryos of apparently normal morphology at the 2-cell $(n=3)$, 8-cell $(n=5)$, 16-cell $(n=5)$, morula $(n=5)$ and blastocyst $(n=5)$ stages were fixed in $2.5 \%$ glutaraldehyde in $0.1 \mathrm{M}$-phosphate buffer (PB), pH 7.2 at $4^{\circ} \mathrm{C}$ for $1 \mathrm{~h}$, then washed with $0.1 \mathrm{M}$-PB, embedded in $4 \%$ agar and post-fixed for $1 \mathrm{~h}$ at $4^{\circ} \mathrm{C}$ in $2 \%$ buffered $\mathrm{OsO}_{4}, \mathrm{pH} 7 \cdot 2$. After rinsing with $0.1 \mathrm{M}-\mathrm{PB}$ and distilled water, embryos were stained in $1 \%$ aqueous uranyl acetate for $1 \mathrm{~h}$ at room temperature, dehydrated, embedded in Spurr, sectioned and stained with lead citrate. Grids were examined in a Philips EM 201 electron microscope at $60 \mathrm{kV}$. Semi-thin sections were stained with toluidine blue.
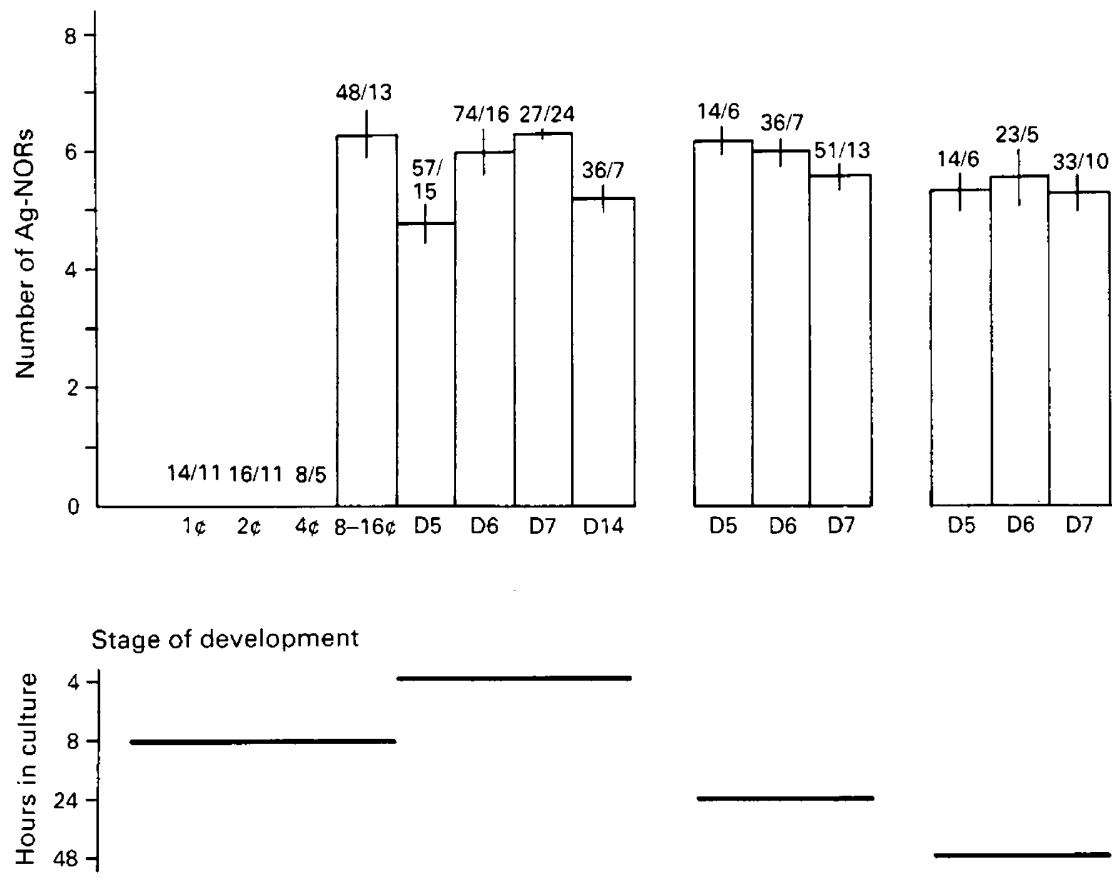

Fig. 1. Number (mean \pm s.e.m.) of NORs per metaphase per bovine embryo collected at various stages of development (number of cells $=\phi$; day of collection $=\mathrm{D}$ ) and cultured in vitro for various periods. The numbers above the histogram indicate the total number of metaphases examined/total number of embryos.

\section{Results}

\section{Cytological observations}

Preparations from a total of 175 embryos (1-cell to elongated blastocyst stage) were selected for staining and examination. Because of the variation in the stage of development among embryos recovered from the oviduct on any given day, the embryos collected between Days 2 and 4 were grouped according to the number of nuclei per embryo that could be counted after fixation. Although there was slight variation in the total number of cells counted after fixation of embryos collected on Day 5 and later, they could be readily classified morphologically as morulae or blastocysts and were grouped according to the day of collection.

The changes in the number of NORs on metaphase chromosomes with age of embryo and time of culture are summarized in Fig. 1. No argentophilic NORs were observed on chromosomes during metaphase II, in pronuclei, during syngamy, or at the 2- or 4-cell stages. However, $6.3 \pm 0.37$ (mean \pm s.e.m.) argentophilic NORs were observed on the chromosomes of 8- to 16-cell stage 

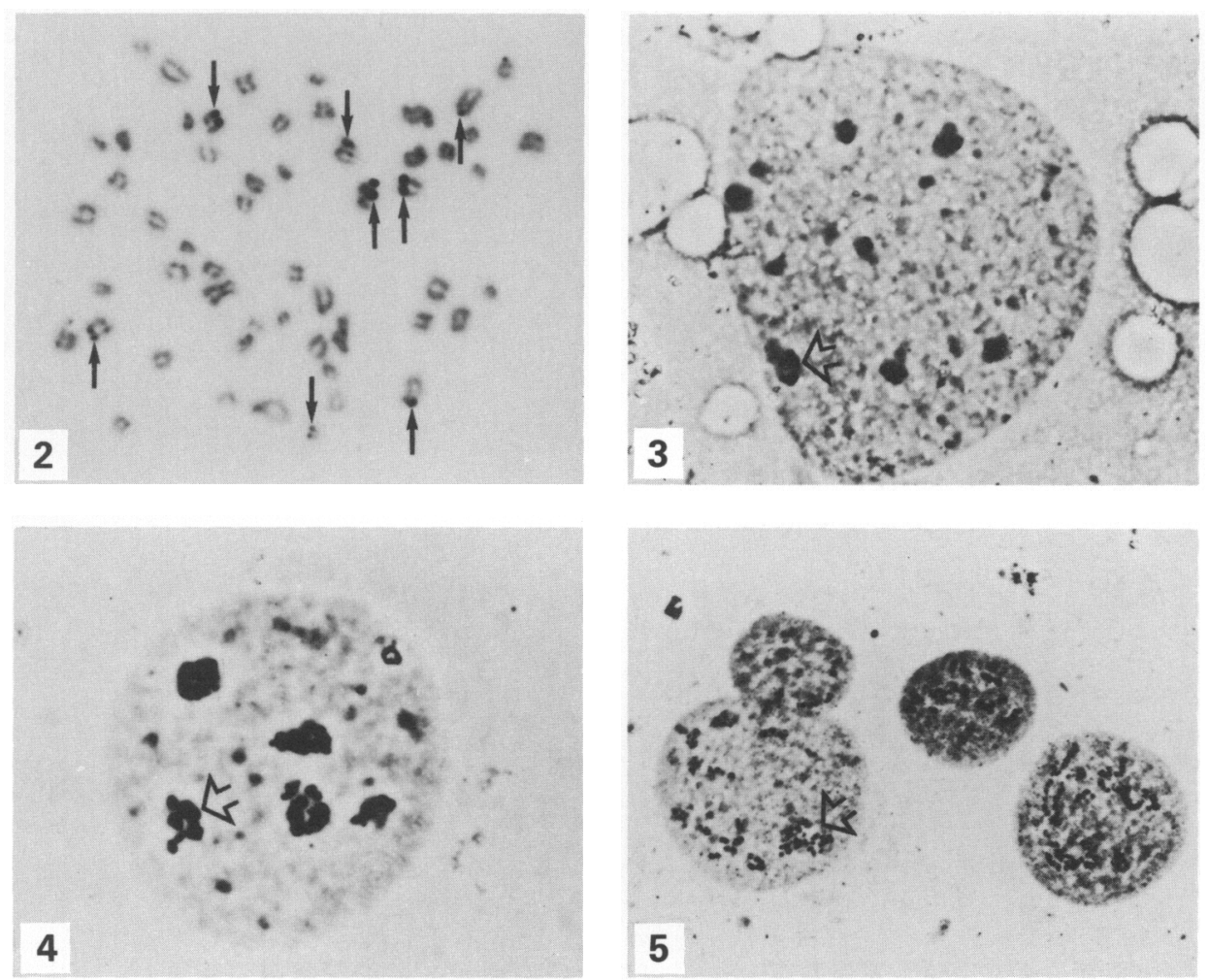

Figs 2-5. Light micrographs of silver nitrate-stained bovine embryo nuclei.

Fig. 2. A metaphase from a 16-cell embryo with Ag-NORs (arrows) evident on 8 chromosomes. $\times 3500$.

Fig. 3. A nucleus from an 8-cell embryo with silver deposits in one or two peripheral regions of the nucleoli (open arrow). $\times 4000$.

Fig. 4. A nucleus from a 16-cell embryo (same as Fig. 2) with several silver deposits on the nucleoli (open arrow). $\times 3750$.

Fig. 5. A nucleus from a blastocyst with many silver deposits throughout the nucleoli (open arrow). $\times 2750$.

embryos and on Days 5, 6, 7 and 14 the numbers of Ag-NORs were $4 \cdot 8 \pm 2 \cdot 6,6 \cdot 0 \pm 0 \cdot 36$, $6.3 \pm 0.14$ and $5.2 \pm 0.23$ respectively. In 2 of the 48 metaphases of the 8-and 16-cell embryos that were analysed, all 10 NOR-bearing chromosomes were stained. The mean number of NORs was not affected by either the stage of development at the time of collection or the length of the culture once the 8-cell stage was passed, except for a significant $(P<0.05)$ increase between Days 5 and 7 for embryos cultured for $4 \mathrm{~h}$ (Fig. 1). A representative metaphase plate is presented in Fig. 2.

The interphase nuclei after hypotonic treatment and fixation varied in size and density. Nuclei of 2- and 4-cell embryos were usually large and diffuse; those from 8-cell and older embryos smaller and more dense. Also, as development progressed, the nucleoli increased in size and affinity for 

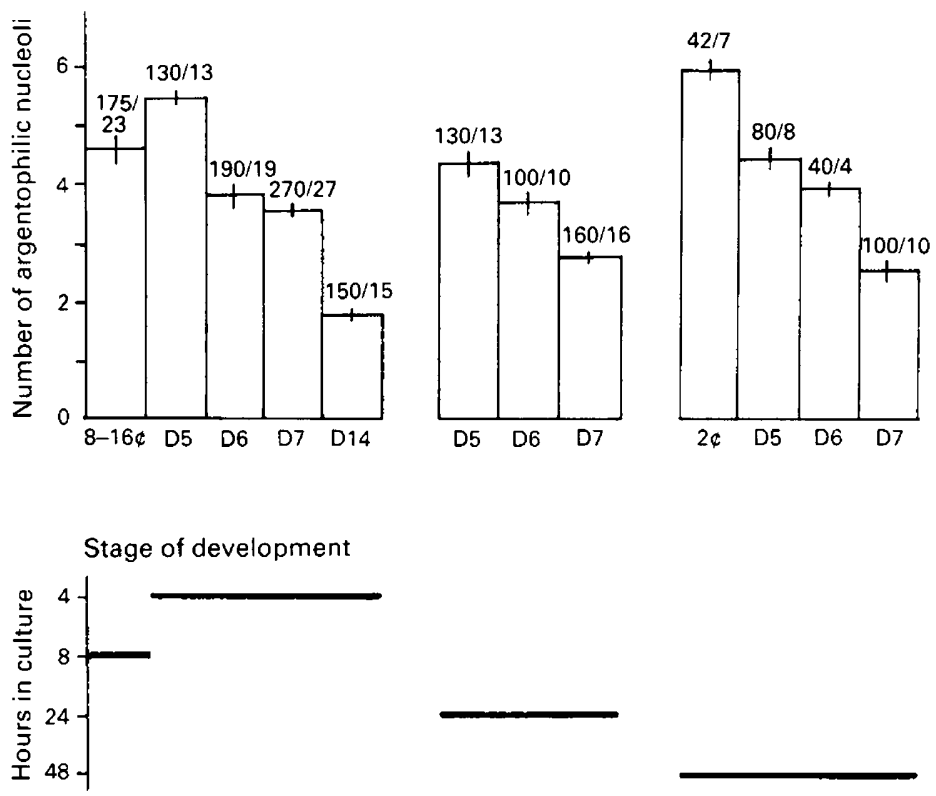

Fig. 6. Number (mean \pm s.e.m.) of nucleoli per interphase per bovine embryo collected at various stages of development (number of cells $=\phi$; day of collection $=\mathrm{D}$ ) and cultured in vitro for various periods. The numbers above the histogram indicate the total number of interphases examined/total number of embryos.

silver and could be divided into four types. Type 1 nucleoli were very small and dense with little or no affinity for silver and were observed only at the 2- and 4-cell stages. Type 2 were smaller, dense nucleoli with one or two dense silver deposits (Fig. 3) and were observed only in the early 8-cell stage embryos in which all 8 nuclei were in interphase. Type 3 nucleoli were small with several silver deposits (Fig. 4) and were found at the late 8-cell stage (when one or more nuclei had progressed to metaphase) and in 9- to 16-cell stage embryos. Type 4 nucleoli were large, often appeared to be fused together, and were characterized by abundant silver deposits throughout their central core (Fig. 5). They were observed consistently in nuclei of all morulae on Day 5, blastocysts on Days 6 and 7 , and elongated blastocysts on Day 14. Type 4 nucleoli were also occasionally found in the nuclei of 9- to 16-cell embryos. The numbers of nucleoli per interphase nucleus at various stages of embryonic development are summarized in Fig. 6. Embryos at the 2- and 4-cell stages could not be included because the nuclei were too diffuse and the nucleoli too small for accurate evaluation. During the short incubations (4- to 8-h) the number of nucleoli per interphase nucleus decreased with development, apparently because of fusion of the large Type 4 nucleoli. A similar decrease in the numbers of nucleoli per interphase nucleus was also observed in embryos collected on Days 5, 6 and 7 and cultured for 24 or $48 \mathrm{~h}$. The seven 2 -cell embryos cultured for $48 \mathrm{~h}$ developed only to the 8 -cell stage and contained only very small nucleoli with one or two dense silver deposits.

\section{Histological and ultrastructural observations}

In semi-thin sections the nuclei of 2-cell embryos were characteristically large with diffuse nucleoplasm and one or two small nucleoli. From the 8-cell stage onward the nucleoplasm was more dense with several nucleoli. The diameters of the nucleoli increased as the number of cells increased. At the ultrastructural level, the nucleoli of the 2-cell embryos were small and composed of a homogeneous dense fibrillar mass associated with chromatin (Fig. 7). In 8-cell embryos they 

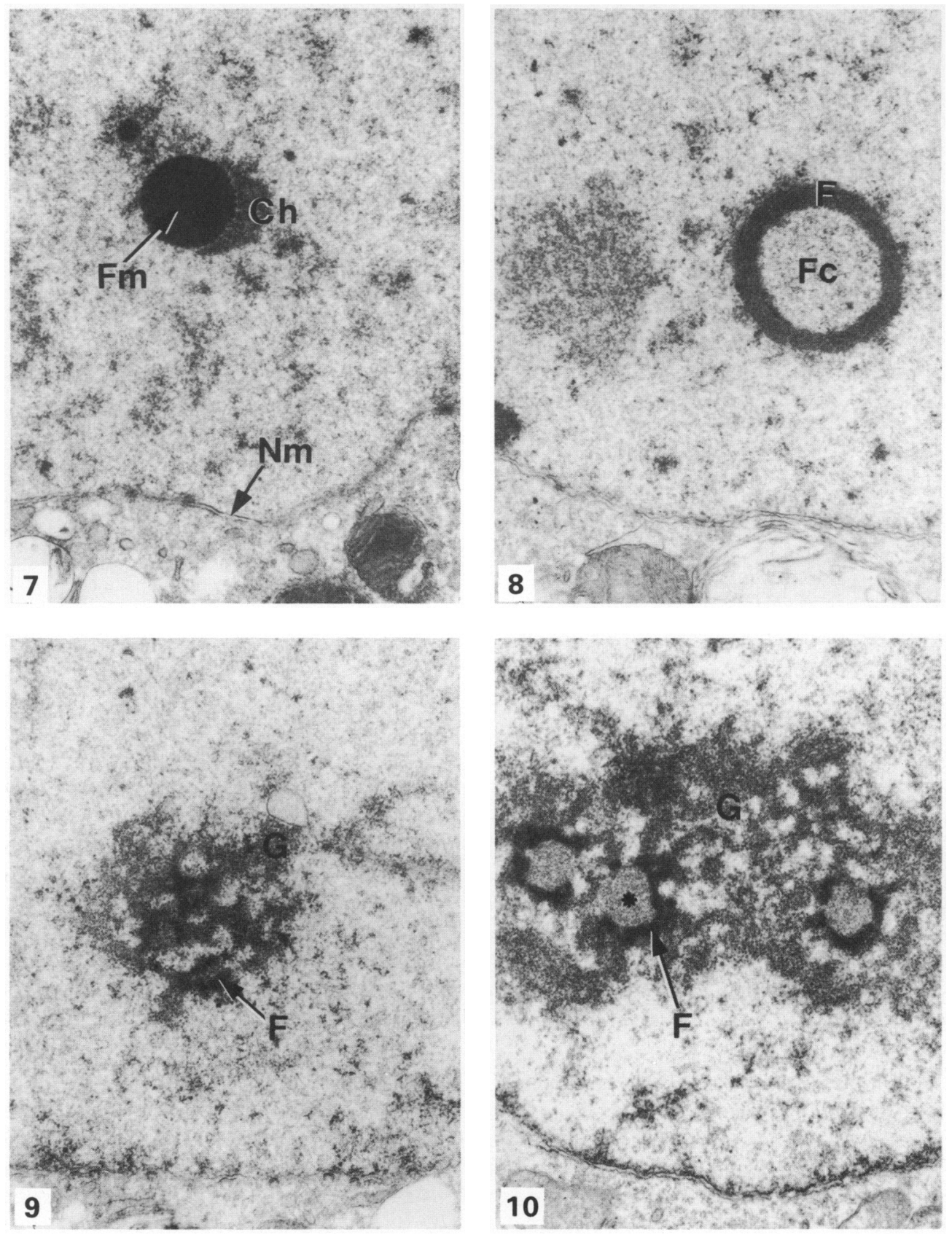

Fig. 7. Nucleolus of a 2-cell embryo showing chromatin $(\mathrm{Ch})$ associated with a dense fibrillar mass $(\mathrm{Fm})$. Nuclear membranes $(\mathrm{Nm}) . \times 15000$.

Fig. 8. Ring-shaped nucleolus of an 8-cell embryo composed of a fibrillar centre ( $\mathrm{Fc}$ ) surrounded by a layer of fibrillar components $(F) . \times 15000$.

Fig. 9. Reticulated nucleolus of a 16-cell embryo composed of fibrillar components (F) and granular components $(G)$. No distinct fibrillar centre can be observed. $\times 15000$.

Fig. 10. Fully developed nucleolus of a blastocyst composed of several fibrillar centres $\left({ }^{*}\right)$, surrounded by fibrillar components (F) and dispersed in prominent granular components $(\mathrm{G})$. $\times 15000$. 
were ring-shaped, contained a single fibrillar centre which presented a different density from the nucleoplasm and was surrounded by a layer of electron-dense fibrillar components (Fig. 8) and were occasionally associated with chromatin. The embryos with more than 16 cells contained reticulated nucleoli with a fibrillar component which was more prominent than at the 8-cell stage and formed a three-dimensional network surrounded by a distinct granular component (Fig. 9). These reticulated nucleoli were almost devoid of fibrillar centres. The nucleoli of morulae and blastocysts were fully developed with several fibrillar centres each surrounded by a layer of dense fibrillar components all within a large mass of granular components (Fig. 10).

\section{Discussion}

Immature oocytes in early antral follicles of cattle are known to synthesize rRNA because they incorporate labelled uridine into their nucleoli, which are large with well developed fibrillogranular elements containing several fibrillar centres (Crozet et al., 1986). As the oocyte matures, rRNA synthesis decreases and the nucleoli become small, homogeneous, composed of an agranular and dense fibrillar core (Crozet et al., 1986). In this study we have observed that a similar transition occurs in reverse after fertilization of the bovine oocyte. At the 2-cell stage the nucleoli were small, and composed of a dense fibrillar core with a low affinity for silver nitrate. At the 8-cell stage the nucleoli were larger and ring-shaped with silver being incorporated into one or two dense regions. By the 9- to 16-cell stage the nucleoli were reticulated, with a greater affinity for silver. The nucleoli of morulae and blastocysts were large, often fused together, and possessed several fibrillar centres, a prominent granular component and numerous silver deposits.

In cultured cells from adult cattle, Ag-NORs have been detected on 10 chromosomes ( 5 autosomal pairs) although the average expression per metaphase is only about 6 (DiBerardino et al., 1979; Henderson \& Bruère, 1979; Mayer et al., 1985). The results of the present study indicate that Ag-NORs first appear at about the 8-cell stage of embryonic development. This is in contrast with the pattern observed in the embryos of mice (Engel et al., 1977; Hansmann et al., 1978) and goats (Chartrain et al., 1986) in which Ag-NORs could be observed on one or more chromosomes at the 2-cell stage, two cleavages earlier than observed in this study. This species difference must be interpreted with some caution because the number of metaphases examined at the 4-cell stage was low. However, it is unlikely that the failure to observe Ag-NORs before the 8-cell stage was due to inadequate staining techniques because older embryos prepared in the same way and at the same time were positive. It may therefore be concluded that the NORs are inactive or have very little activity before the 8-cell stage. Once the Ag-NORs become detectable at the 8-cell stage in the embryos of cattle, they appear to be expressed heterogeneously because, from the first, all 10 chromosomes known to bear Ag-NORs in the adult were also occasionally seen to be involved in the embryonic cells. This heterogeneity would also account for the general lack of statistically significant differences in the numbers of Ag-NORs as development progresses (Fig. 1). It must also be remembered that, although the presence of Ag-NORs reflects rRNA transcription qualitatively, quantitative differences in the active rDNA are not necessarily reflected in Ag-NOR numbers (Schwarzacher et al., 1978).

The contention that rRNA (18S and 28S) genes become transcriptionally active at the 8-cell stage in the bovine embryo is also supported by the cytological and ultrastructural observations of the nucleoli at the same time as Ag-NORs made their appearance. Others have also suggested that rRNA synthesis resumes at the 8-cell stage in bovine embryos (Camous et al., 1986). Again, there may be differences between species since ultrastructural studies of the nucleoli have led to the speculation that rRNA synthesis is initiated at about the 16-cell stage in sheep (Calarco \& McLaren, 1976) while in pigs such changes are observed at the 4-cell stage (Norberg, 1973) when a prolonged lag in cleavage is observed in vivo (Hunter, 1974). That those changes represent the time of initiation of RNA synthesis is supported by the fact that tritiated uridine incorporation into 
RNA was first detected at the 4-cell stage in the pig and in the human uridine incorporation is also first detected at the 4-cell stage (Tesarik et al., 1986).

In cattle the 8-cell stage seems to be considerably longer than the 2-, 4- or 16-cell stages in vivo (see Fig. 1 of Betteridge, 1977) and few embryos placed in culture before this stage develop through the '8-cell block' (Camous et al., 1984; Eyestone \& First, 1986), as was also observed with the 2-cell embryos cultured in this study. This block can be partly overcome by co-culture of 1-, 2-, 4- and 8-cell stage embryos with trophoblastic vesicles (Camous et al., 1984). A similar block to in-vitro development occurs at the 2-cell stage in outbred strains of mice and this block can be overcome by injecting cytoplasm from embryos of strains that do not exhibit this block into embryos of susceptible strains (Muggleton-Harris et al., 1982) or by culturing them in oviducts, in an organ culture system (Whittingham \& Biggers, 1967) or in vivo (Papaioannou \& Ebert, 1986). The block to in-vitro development occurs in both species about when NORs first become transcriptionally active. It has been suggested that, for cattle embryos, the 8-cell stage is a particularly sensitive stage of development that requires factors that are normally present in vivo, or are produced by older embryos, but which are lacking in culture systems in vitro (Camous et al., 1984). When considered in relation to the evidence from the present study, it seems possible that these factors may play an essential role in the initiation of transcription of embryonic genes.

Bovine embryos that have passed the 8-cell stage in vivo can be more readily cultured in vitro for 1 or 2 days in simple media, undergoing apparently normal compaction, blastulation and hatching (Wright \& Bondioli, 1981). The embryos collected on Days 5,6 and 7 in this study and cultured for 24 or $48 \mathrm{~h}$ were typified by Ag-NORs and argentophilic nucleoli which showed no discernible difference from those examined after only a very brief $(4 \mathrm{~h})$ culture period. Taken together, these separate observations suggest that, once the rRNA genes become transcriptionally active, their activity can be maintained in vitro without the presence of the factors presumed to be essential for their activation.

It is generally presumed that late 8-cell embryos are easier to culture than are early 8-cell embryos, but it is also recognized that there are no reliable criteria for distinguishing between them (Seidel, 1977; Camous et al., 1984). The morphological features of the nucleolus may represent such a criterion, besides providing some indication of transcriptional activity of rRNA genes in individual cells.

At the 2-cell stage in mouse embryos, significant transcription of the embryonic genome has been detected and it is thought to signal the beginning of embryonic control of development (Bolton et al., 1984). The 8-cell stage in cattle embryos may be analogous to the 2-cell stage in mouse as being the time of transition from maternal to embryonic control of development but further studies are required to determine to what extent the genome of the bovine embryos may be active before the 8 -cell stage.

This research received the financial support of Natural Sciences and Engineering Research Council of Canada (NSERC), and 'Fonds pour la Formation de Chercheurs et l'Aide à la Recherche (FCAR)'. A scholarship from Ministère de l'enseignement supérieur d'Algérie (N.A.) is acknowledged. We thank Mireille Blaquière for technical assistance; Hélène Boucher, Sylvie Lagacé and Linda Leduc for typing the manuscript; and Dr A. K. Goff, Dr N. First, Dr F. Barnes and Dr W. Eyestone for fruitful discussions.

\section{References}

Betteridge, K.J. (1977) Techniques and results in cattle. In Embryo Transfer in Farm Animals. A review of Techniques and Applications. Ed. K. J. Betteridge. Canada Dept. of Agriculture, Monograph 16.
Betteridge, K.J. \& Mitchell, D. (1974) Embryo transfer in cattle: experience of twenty-four completed cases. Theriogenology 1, 69-82.

Bloom, S.E. \& Goodpasture, C. (1976) An improved 
technique for selective silver staining of nucleolar organizer regions in human chromosomes. Hum. Genet. 34, 199-206.

Bolton, V.N., Oades, P.J. \& Johnson, M.H. (1984) The relationship between cleavage, DNA replication and gene expression in the mouse 2-cell embryo. $J$. Embryol. exp. Morph. 79, 139-163.

Calarco, P. \& McLaren, A. (1976) Ultrastructural observations of preimplantation stages of the sheep. $J$. Embryol. exp. Morph. 36, 609-622.

Camous, S., Heyman, Y., Méziou, W. \& Ménézo, Y. (1984) Cleavage beyond the block stage and survival after transfer of early bovine embryos cultured with trophoblastic vesicles. J. Reprod. Fert. 72, 479-485.

Camous, S., Kopecny, J. \& Fléchon, J.E. (1986) Autoradiographic detection of the earliest stage of $\mathrm{H}^{3}$ uridine incorporation into the cow embryo. Biol. Cell 58, 195-200.

Chartrain, I., Niar, A., King, W.A., Picard, L. \& St-Pierre, H. (1986) Nucleoli and nucleolus organizer regions (NORs) in early goat embryos. Theriogenology 25, 145, Abstr.

Croce, C.M., Talavera, A., Basilico, C. \& Miller, O.J. (1977) Suppression of production of mouse $28 \mathrm{~S}$ ribosomal RNA in mouse-human hybrids segregating mouse chromosomes. Proc. natn. Acad. Sci. U.S.A. 74, 694-697.

Crozet, N., Kanka, J., Motlik, H. \& Fulka, J. (1986) Nucleolar fine structure and RNA synthesis in bovine oocytes from antral follicles. Gamete Res. 14, 65-73.

DiBerardino, D., Arrighi, F. \& Kieffer, N.M. (1979) Nucleolus organizer regions in two species of bovidae. J. Hered. 70, 47 - 50 .

Engel, W., Zenzes, M.T. \& Schimid, M. (1977) Activation of mouse ribosomal RNA genes at the 2-cell stage. Hum. Genet. 38, 57-63.

Eyestone, W.H. \& First, N.L. (1986) A study of the 8to 16-cell developmental block in bovine embryos cultured in vitro. Theriogenology 25, 152, Abstr.

Fakan, S. \& Odartchenko, N. (1980) Ultrastructural organization of the cell nucleus in early mouse embryos. Biol. Cell 37, 211-218.

Geuskens, M.J. \& Alexandre, H. (1984) Ultrastructural and autoradiographic studies of nucleolar development of rDNA transcription in pre-implantation mouse embryos. Cell Diff. 14, 125-134.

Goessens, G. (1984) Nucleolar structure. Int. Rev. Cytol. 87, 107-158.

Hansmann, I., Gebauer, J., Bihl, L. \& Grimm, T. (1978) Onset of nucleolus organizer activity in early mouse embryogenesis and evidence for its regulation. Expl Cell Res. 114, 263-268.

Henderson, L.M. \& Bruère, A.N. (1979) Conservation of nucleolus organizer regions during evolution in sheep, goat, cattle and aoudad. Can. J. Genet. Cytol. 21, $1-8$.

Hunter, R.H.F. (1974) Chronological and cytological details of fertilization and early embryonic development in the domestic pig, Sus scrofa. Anat. Rec. 178, 169-186.
Kidder, G.M. \& McLachlin, J.R. (1985) Timing of transcription and protein synthesis underlying morphogenesis in preimplantation mouse embryos. Devl Biol. 112, 265-275.

King, W.A., Linares, T., Gustavsson, I. \& Bane, A. (1979) A method for preparation of chromosomes from bovine zygotes and blastocysts. Vet. Sci. Commun. 3, 51-56.

King, W.A., Niar, A. \& Betteridge, K.J. (1985) The nucleolus organizer regions of early bovine embryos. J. Dairy Sci. 68, Suppl. 1, 249, Abstr.

Mayer, B., Schweizer, D., Mendelak, M., Krutzler, J., Schleger, W., Kalat, M. \& Auer, H. (1985) Levels of conservation and variation of heterochromatin and nucleolus organizers in the Bovidae. Can J. Genet. Cyol. 27, 665-682.

Muggleton-Harris, A.L., Whittingham, D.G. \& Wilson, L. (1982) Cytoplasmic control of preimplantation development in vitro in the mouse. Nature, Lond. 299, 460-462.

Norberg, H. (1973) Ultrastructural aspects of the preattached pig embryo: cleavage and early blastocyst stages. Z. Anat. EntwGesch. 143, 95-114.

Papaioannou, V.E. \& Ebert, K.M. (1986) Development of fertilized embryos transferred to oviducts of immature mice. J. Reprod. Fert. 76, 603-608.

Romagnano, A., King, W.A., Richer, C.-L. \& Perrone, M.-A. (1985) A direct technique for preparation of chromosomes from early equine embryos. Can. $J$. Genet. Cytol. 27, 365-369.

Schwarzacher, H.G., Mikelsaar, A.V. \& Schnedl, W. (1978) The nature of the Ag-staining of nucleolus organizer regions. Cytogenet. Cell Genet. 20, 24-39.

Seidel, G.E., Jr (1977) Short-term maintenance and culture of embryos. In Embryo Transfer in Farm Animals. A Review of Techniques and Applications, pp. 20-24. Ed. K. J. Betteridge. Canada Dept. of Agriculture, Monograph 16.

Smetana, K. \& Busch, H. (1974) The nucleolus and nucleolar DNA. In The Cell Nucleus I, pp. 73-147. Ed. H. Busch. Academic Press, New York.

Tesarik, J., Kopecny, V., Plachot, M. \& Mandelbaum, J. (1986) Activation of nucleolar and extra nucleolar RNA synthesis and change in ribosomal content of human embryos developing in vitro. J. Reprod. Fert. 78, 463-470.

Wachtler, F., Ellinger, A. \& Schwarzacher, H.G. (1980) Nucleolar changes in human PHA stimulated lymphocytes. Cell Tiss. Res. 213, 351-360.

Whittingham, D.G. \& Biggers, J.D. (1967) Fallopian tube and early cleavage in the mouse. Nature, Lond. 213, 942-943.

Winer, B.J. (1971) Statistical Principles in Experimental Design. McGraw-Hill, New York.

Wright, R.W., Jr \& Bondioli, K.R. (1981) Aspects of in vitro fertilization and embryo culture in domestic animals. J. Anim. Sci. 53, 702-729.

Received 17 March 1987 